INAUGURAL LECTURE ON MEDICAL STATISTICS: A MICROSCOPE FOR HEALTH AND DISEASE

BY

\author{
PROF. E. A. BAMGBOYE \\ DEPARTMENT OF EPIDEMIOLOGY, \\ MEDICAL STATISTICS AND \\ ENVIRONMENTAL HEALTH (EMSEH) \\ COLLEGE OF MEDICINE, \\ U.C.H., IBADAN
}

The Vice-Chancellor, Deputy Vice-Chancellors (Administration and Academic), The Registrar, The Librarian, Provost, College of Medicine, Dean of the Faculty of Public Health, Dean of the Postgraduate School, Dean of other Faculties and of Students, Distinguished Guests, Ladies and Gentlemen.

I am grateful to God Almighty for the honour and privilege to be selected to deliver the 2005/2006 inaugural lecture on behalf of the Faculty of Public Health. The feeling of honour and privilege stems from the fact that if the Faculty of Public Health had not been created in 2002, I may not have had the opportunity of giving an inaugural lecture before retirement despite attaining the position of Professor 14 years ago.

This inaugural lecture is the fourth from the Faculty of Public Health and second from the Department of Epidemiology, Medical Statistics and Environmental Health (EMSEH). The first lecture was by Prof. J.D. Adeniyi from the Department of Health Promotion and Education, the second was from Department of EMSEH by Prof. M.C.K. Shridhar, a Professor of Environmental Health and the third was by Prof. O.O. Keshinro of the Department of Human Nutrition while the fourth one is also from the Department of EMSEH by a Professor of Medical Statistics. I can therefore predict with $95 \%$ confidence that the next inaugural lecturer from the Department of EMSEH will be by a Professor of Epidemiology.

When I received the e-mail from the Dean of the Faculty of Public Health, Prof. Olaolu Akinyele that I had been nominated to give the 2005/2006 inaugural lecture on behalf of the Faculty I readily accepted. I was then at the John Hopkins University School of Public Health as a visiting scholar. Since I was to send a topic immediately, I started to ponder on the topic and that night I had a dream in which I received the title of today's inaugural lecture which is "Medical Statistics, a Microscope for Health and Disease".

What Really is Medical Statistics, One May Ask? Mr. Vice-Chancellor sir, as I ponder on this title many days later, I realized that Medical Statistics as the Science of counting health and disease, making sense out of those counts and foretelling what lies ahead is actually a microscope into health and disease. Previously,
Medical Statistics was only concerned with enumerating those dying in relation to those living, but there has been a paradigm shift as facts and impressions in Medicine are now expressed in numerical forms. This includes laboratory investigations, radiological investigations and clinical observations. In short, the methods by which these numerical facts on health and disease are collected, manipulated, sieved, summarized and interpreted, making use of the whole armamentarium of statistical theories is the subject known as Medical Statistics (Chiang, 1985, Zellen, 1983).

The World Health Organization defined health "as a state of complete physical, mental, spiritual and social well-being and not only or merely the absence of disease". Therefore, the question that comes to mind is: How does one know who satisfies this definition of health? In other words, who is healthy? Or can we assume that anyone who has not sought help from any health care service is healthy? The answer is NO. Or else how do you explain the case of a man who had never complained of any sickness in the last 5 years or so, but suddenly dropped dead after seeing off a visitor. We all know that many people suffer from one kind of ailment or the other in silence partly because they do not know that they are sick. The truth of the matter is, there is a subtle difference between health and ill-health that cannot be seen with naked eye and this suggests that we need a microscope to identify the ailment. Medical Statistics utilizes relevant, reliable and valid information to identify the significance of any difference at a known probability and has been the most useful microscope in this respect. Thus, the demographic information, medical history, clinical signs and symptoms collected to aid the diagnosis of any disease is germane to sound statistical manipulation. Population Medicine informs that diseases or deaths do not occur at random. They are cause, though not by witchcraft nor the 'worst' of the 'wicked'.

Mr. Vice-Chancellor sir, this inaugural lecture has been carefully designed to focus not only on how best medical statistics has acted as a microscope to detect health and disease of people in the community but on the factors casing the disease. Perhaps some of us who are familiar with Epidemiology as the study of the frequency, distribution, determinants and deterrent of diseases in human populations would wonder if Medical Statistics is not taking up that definition. Suffice to say that this microscope (medical statistics) is used for both the community diagnosis of ill-health and the diagnosis of disease of an individual. Both public health and disease and of course information is knowledge and knowledge is power.

\section{Medical Statistics and Epidemiology}

Medical Statistics as a discipline in Public Health and Medicine represents one of the major intellectual advances of the twentieth-century. It has developed to initiate and strengthen the collaboration of statisticians and health professionals (particularly physicians) in any medical or health research. Suffice 
to say that a medical statistician is at first a mathematician who adapts his knowledge to the study of disease. Although the study of disease could be said to be mainly in the allied discipline of Epidemiology, the epidemiologist and the statistician work together to the extent that it is permissible to use the words "Statistical" and "Epidemiological" interchangeably.

The epidemiologist is first all (in most cases) skilled in medicine, but adopts a mathematical approach to the study of disease in the population. The working relationship of medical statisticians and epidemiologist has resulted in the statistician become a better epidemiologist and the epidemiologist a better statistician both using numbers and their logic to unravel the mystery behind diseases. According to Professor Healy of the London School of Hygiene and Tropical Medicine, "the difference between epidemiologists and statisticians is a subtle one......as it is one emphasis" (Healy, 1977: Zeger, 1991). While epidemiologist is mainly interested in the results of investigations, irrespective of the methods by which these results were obtained, medical statisticians are also interested in results but equally in the methodology of obtaining them. The medical statistician, because of his mathematical background often develops new and modified techniques for handling specific medical data or results in a novel application of methods developed in another field.

The University of Ibadan, since 1968, as employed a medical statistician with background in mathematical statistics in its medical school and this has improved tremendously, the quality of medical research as collaboration between the medical statistician and medical doctors become a routine affair. The development and relevance of the discipline of medical statistics as a component course in medicine is such that there is a full department with its complement of medical statisticians in Ibadan. It is not only that medical statistics is part of the curriculum in both undergraduate and postgraduate medical education, but people now acquire postgraduate degrees in medical statistics and statistical epidemiology from the University.

\section{Medical Statistics and Community Diagnosis of Health}

Public Health is concerned with the health of the entire population as a whole, but the clinician is interested only in the treatment of that individual who has approached him because of ill-health. Public Health strategies are largely designed to prevent ill-health, identify and treat promptly those with ill-health, thus avoiding any serious consequences. As an illustration of the main focus of public health and also of clinical medicine, public health tends to find out why many sick people from, say Oja-Oba in Ibadan come to the health centre with diarrhea diseases and a very negligible number come from, say Bodija with this condition. In this scenario, the clinician's primary duty is to treat cases of diarrhea that come to his clinic on a 1-1 basis, but the public health person traces the people to their community to find out possible risk factors present in the areas they have come from. If he later discovers that people from Oja-Oba take their drinking water from a source polluted by Ogunpa River and those from Bodija from well-treated pipe borne water, he can associate the higher prevalence of diarrhea with the source of drinking water, more so if the difference in the proportion with diarrhea between the two groups is statistically significant. In fact, this is how John Snow linked cholera to contaminated water and thousands of people are being prevented from this deadly disease by providing them with good portable water. One clear difference between the impact of the strategies of clinical medicine and preventive medicine is the number of people affected at a time. While the clinicians may see an average of 10 patients a day in a medical out-patient clinic, a preventive action may affect and save the lives of several millions of people.

Medical Statistics also develops mechanisms to find the causes of diseases or at lease locate modifiable and non-modifiable risk factors, whether environmental, behavioral, occupational hazards and other factors that could pre-dispose to the occurrence of diseases. Imagine seeking for risk factors of diseases in a population as large as Nigeria with over 130 million people. This is like fishing in the dark and Medical Statistics has provided the microscope for making correct community diagnosis of ill-health and examining if those who are apparently healthy may probably be so because they have not shown any signs or symptoms of any disease or that they are truly healthy. If they are healthy, the microscope examines measurement of such factors that make them healthy. The diseases are classified into communicable and noncommunicable diseases for ease of understanding and presentation. This is further classified into seventeen categories ranging from infectious and parasitic diseases to accidents and ill-defined conditions.

The development of statistical indices of health such as rates, with the four components - numerator (no. of events, of interest), denominator (population at risk of the event), timeframe (the period the events occurs) and the standard form in which it is expressed has found immense use in determining health and disease status. The size or extent or magnitude of a disease or any health problem in the community can be measured by the prevalence rate. But the rapidity at which diseases occur in the population on the other hand is measured by the incidence rate. The census, a purely statistical exercise that is routinely conducted every ten years in any developed nation provides sources of the denominator for most of our rates. The collection and analysis of records of vital events such as births, marriages and deaths have been used to assess fertility, nuptiality, mortality and growth of human population. Thus, the ability to measure is paramount (sine qua non) to understanding health and disease and this has been facilitated by the science of medical statistics. In fact as far back as 1889, Lord Kelvin had written that 
"when you can measure what you are speaking about, and express them in numbers, you know something about it; but when you cannot measure it, when you cannot express them in numbers, your knowledge is of a meager and unsatisfactory kind" (Oldham, 1968).

\section{Medical Statistics as a Microscope for Individual Diagnosis}

Medical Statistics as a microscope for individual diagnosis of disease, its prognostic factors and best treatment options was resisted at its earlier debut in clinical medicine. The notion of clinical doctors is that "patients are different and therefore cannot be subjected to statistics". A clinician even said that if he has done a study and requires statistics, then he knows he has done a bad study. But can anyone in this audience tell if the person sitting next to him or her is healthy? Do you know if a healthy looking man has AIDS? Or can you say if that well-built man next to you can be hypertensive? Is the woman on your left side suffering from diabetes? The truth is that there is no window to look into the system or heart of man to identify a healthy man, or to know if a drug will cure a disease, or know the cause of a disease, or know who will die in the next minute demand more than what can be seen with naked eye. The naked eye of the doctor cannot tell if the social habit of a patient is responsible for that damage in the liver. And neither can the naked eye of the doctor nor that of the nurse tell if the patient admitted for diabetic care will survive the next 3 days. Neither could the naked eye see the exact diagnosis of the illness of a peasant farmer from a village in Ekiti State who suddenly jumped on the road, claiming himself as the president of the USA and asking people and relatives around him to take commands from him.

Mr. Vice-Chancellor sir, God created man to be different in many respects from each other and one clear evidence is that no two fingerprints of the over 6.5 billion people in the world are the same. These inherent biological variations in man and the differences in characteristics of individuals would have made it more difficult to find the truth of the actual factors causing or affecting ill-health and diseases' worst outcome - death. But God so loved the world that He created the science of medical statistics and medical statisticians to sort out the variations in man and disease and thus able to identify the true causes or risk factors of ill-health and death to specified degrees of confidence. But it was initially difficult for clinicians to imbibe medical statistics as a reliable and valid microscope to diagnose diseases.

However, by and large, the concept of medical statistics realized ironically as far back as the $16^{\text {th }}$ century by some people has now become the norm rather than the exception in medical practice. Leonardo Da Vinci who lived in the $16^{\text {th }}$ century $(1452-1519)$ said "No human investigation can be called true science without passing through statistical test". Medicine has become real science. The clinical issues of patient diagnosis, prognosis of disease and treatment have benefited from medical statistics. Diagnosis and assessment of prognostic factors depend largely on patients' data on physical characteristics, laboratory parameters, radiological information, clinical and personal characteristics. The 3-stage process of science, observations, building up a model to describe or explain the model and using the model to predict future observations or events have found a strong place in medicine particularly in communicable disease where epidemics are dealt with. The use of models in describing any epidemic and forecasting the spread in time if nothing is done is the telescopic use of Medical Statistics.

\section{Normal Range of Values}

The commonly used concept of normal range of values for separating healthy people from those who are diseased has been facilitated by the microscopic nature of medical statistics, starting from its use of "mean plus or minus two standard deviations" based on the assumption of a Gaussian distribution for continuous variables. The diagnosis of most medical ailments such as diabetes, hypertension, anemia and so on depend much on the normal range of values of biochemical parameters, blood pressure readings and hematological indices obtained from the patients. Thus the doctor can classify as hypertensive with a high degree of confidence, a 50 year old man with three consecutive blood pressure readings of 180/100, 178/ 95, 181/100. Or as diabetic, a middle-aged woman with fasting blood sugar of $180 \mathrm{mg} / \mathrm{dl}$; and random blood sugar of $200 \mathrm{mg} / \mathrm{dl}$ and a young man with CD4 count of 150 as suffering from AIDS. Also, the doctor can say that a woman with a white blood cell count of 320,000 per $\mathrm{ml}$ may be suggestive of myeloid leukaemia or a child with a temperature of 39.3 degrees as having a fever. The doctor can also diagnose a 20 year old girl with PCV of $10 \%$ as severely anemic.

But the so-called concept of normal range of values often used, is developed on the normal distribution theory, an important aspect of medical statistics that has been very useful as a microscope to sort out patients into normal and abnormal groups or healthy and disease group.

Using the properties of the model, the parameters were calculated from observed values in an apparently healthy population. Subsequently, confidence intervals for which admissible values with 95\% confidence are allowed are obtained and consequently the construction of the normal range of values. It suffices to say that this simple mathematical model is the bedrock of parametric tests which have found immense use today in the testing of hypotheses. Clinicians have drunk so deep of the statistical concept of hypothesis testing to have developed a p-value syndrome to an extent that they have felt that any research in Medicine cannot be published without an accompanying $\mathrm{p}$-value. This may not necessarily be so as some studies are purely descriptive and do not test any hypothesis. 


\section{Evaluation of Treatments}

Also, apart from identifying health and disease, Medical Statistics or the Medical Statistician has always acted as a policeman in medical practice. We are in a world of great advancement in computer technology and the practice of medicine has become evidence based. The patients in the hospital want to know the treatment plan for them, at least to have psychological satisfaction. Astute observations of regularities of events often call for clinical or epidemiological studies. Mr. A had this problem, received drug A and was relieved. But Mr. $\mathrm{B}$ had the same problem, was given drug A but did not improve. Medical Statistics provides the path of explanation; first, it asks if the disease condition is similar in both groups in terms of onset before seeking treatment and then finds out if the drug works in the acute or chronic phase, or whether confounders in terms of the persons of $\mathrm{Mr}$. A and $\mathrm{B}$ have been removed. Thus, clinicians are reminded that the measurements collected are subject to variations and interpretations and can be marred by confounding factors if these are not properly controlled for. Factors masking the true diagnosis or the true efficacy of any therapy are sorted out and removed through the use of Medical Statistics, the powerful microscope for health and disease.

This microscope is not only towards health and disease but also to allied areas where the truth is needed. Such is the performance of students in the universities and their admission criteria. My work in this area has been in examining the University of Ibadan as a case study. This effort resulted in the present admission guidelines for Post-UME screening referred to as the Ibadan Model. (Bamgboye 1981; Bamgboye et al., 2001; Kale and Bamgboye, 1984; Screening Committee, 2005)

Medical Statistics as a Microscope for the Truth I was privileged to attend the 2002/2003 University lecture delivered by Professor Oladele Kale, an icon in Public Health and in particular filariasis, the foundation Dean of the Faculty of Public Health who was my Head of Department (HOD) at several points in the life of the Department of Preventive and Social Medicine, including the period of 'distress'. He emphasized the need to seek the truth always in that lecture titled "Nigeria in Distress! A Trilogy of the Nation's Health Status". The apostle John said in John 41; "Dear friends, do not believe every spirit, but test the spirits to see whether they are from God, because many false prophets have gone out into the world". Indeed, in a similar fashion, many false (unscientific) researchers have flooded the health field and have always capitalized on the psychology of the people to inflict untold story on them. I have watched several times on my television, and advertisement of a magic drug (panacea) that can treat typhoid, hypertension, appendicitis and any other disease (just name it) with a single dose!

Professor Kale used the Abalaka claim of a prophylactic and therapeutic cure for HIV/AIDS as a case study. This is a well known case circulated on the pages of newspaper a few years ago. Because of the deadly nature of AIDS and the fact that no cure is known, it is normal to draw attention to anyone who announces he has found a cure. No doubt, a microscope is needed to ascertain the minute details of the truth of any claim to a cure of AIDS. And indeed, if you ask me the sample size required to assess the efficacy of a drug that could cure AIDS, I would say one person. But then the one person must indeed be diagnosed to truly have AIDS and all the facts must be available.

As usual, the Abalaka drug issue was reviewed by Professor Kale, and many people including myself ended up disappointed at the methods of investigation by all the parties concerned. But the Abalaka issue is a tip of the iceberg in the multitude of malpractices involving the inappropriate use of Medical Statistics that pervades our health service system. This is often attributed to inadequate knowledge of the real health problem, the root cause of which is the poor data gathering system, method of data analysis, and poor interpretation of findings. This is the situation in which any nation will find itself when there is a lack of reliable empirical evidence to aid decision making and those trained to provide the mechanism to generate this reliable data are either not available or are very few. It is not surprising however, for one to grope in the dark when that instrument to provide light and see minutest issues as a microscope is missing. Our Lord Jesus Christ saw the crowd following Him at one stage and had pity on them and declared in Mathew 937; "The Harvest is plentiful but the workers are few". For the multitude of health problems that need research all over the world and in particular in Nigeria, there are few medical statisticians.

The advancement of computer technology and the availability of statistical packages in the open market, with piracy going on unchecked, have given birth to a number of do-it-yourself statisticians. These people who often 'hit their thumbs with hammer' in their practice do more damage than I will cause if I attempt a brain surgery. There is no amount of formal education a health policy maker can acquire that he will be able to draw up meaningful policies based on wrong data or subjective reasoning. We all know that the bane of our health problems in Nigeria today is the lack of reliable health data and lack of professional medical statistician in the health system team. If this was not so, the Nigeria Institute of Pharmaceutical Research and Development (NIPRD) would have had at least one medical statistician on their team, who would have advised the director investigating Abalaka claim based on two patients, that they needed to include a control patient probably on a placebo and see the natural course of the disease.

In clinical trials, a great deal of attention is directed at the patient and they are much aware of this and subjects' condition can change because of this and not necessarily because of any treatment. This situation, known as the Hawthorne effect cannot be separated 
from the treatment effect in uncontrolled trials as carried out in NIPRD. God is wonderful; there is the natural course of things and medical statisticians have studied this situation to conclude obedience to the "Law of regression to the mean". This explains why clinicians require a repeat of a laboratory test of an unexpectedly abnormally high value and usually, the second test result is closer to normal values. Anyway, a cure for a disease as deadly as AIDS may not attract any large sample size as I said before, a sample size of one is enough if people can truly attribute the cure of AIDS disease to the 'curative agent' alone. The statistical methods for the evaluation of treatments of diseases date back to the early life of man. In the Holy Bible (Judges $6^{36-40}$ ), Gideon wanted to know if God would indeed support him in the task He put before him. Then he carried out a trial by putting a fleece of wool on the floor and asking God to make the fleece only wet and the earth around it dry. It happened, but he reversed his allocation of subject units and asked God to make the fleece of wool dry and make the surrounding earth wet. This happened and he was convinced beyond any reasonable doubt that God would support him. This design can be taken as the beginning of the crossover design often used in clinical trials today.

Let me tell you the story of the blind man and the dumb man brought to Jesus. The dumb man was demon-possessed and could not talk and everyone in the crowd knew this and so also the blind man. They deliberately brought them to Jesus, probably to test His power. The blind man regained his sight and Jesus drove the demon out and the dumb man also regained his speech. According to Matthew $9^{33}$, “...........the crowd was amazed and said nothing like this has ever been seen in Israel". In spite if the several miracles using the same therapy, many people were still skeptical about Jesus and His therapy. The medical statistician is always a skeptical scientist.

Now, about Abalaka's drug trial, I reproduce in table 1 the NIPRD result with permission from my former HOD. The changes may simply be the whole concept of regression to the mean.

Table 1: NIPRD Result on Abalaka's Drug Trial After two weeks of immunotherapy Viral load (copies/ml) NIPRD/HIV/JAV/001NIPRD/HIV/JAV/002 $8.2 \times 10^{5}(12 / 1 / 2000) 1.6 \times 10^{5}(12 / 1 / 2000)$ $2.4 \times 10^{3}(25 / 1 / 2000) 1.6 \times 10^{3}(25 / 1 / 2000)$

The medical statistician would have suggested the need for a control group and asked many other questions if he were on the research team. What is the viral load of the AIDS patient who never took Abalaka's drugs? Are the patients truly comparable or do they satisfy the same criteria for inclusion? Any ambiguity in the definition of AIDS? Have they used the same selection criteria or mechanism for counting the viral load? Are there copying errors, transcription errors, measurement errors? And so on. Apostle Paul said in John 8 verse 32; "if we know the truth, the truth shall set us free".
Since the naked eye cannot see the truth in health and disease and we must know the TRUTH, we give Glory to God for the birth of the discipline of MEDICAL STATISTICS to serve as a MICROSCOPE to tell the truth about health and disease.

Let me at this point appreciate Professor Bamiduro who defined Statistics in his inaugural lecture of $7^{\text {th }}$ July 2005 "as the science to detect the TRUTH". Several strategies have been put in place by man (preventive, curative) to ensure that everyone is healthy. But the organization of these strategies has benefited immensely from the use of the science of Medical Statistics. That the psychiatrics is able to define variables associated with maniac depression, and the surgeon able to measure the degree of burns or the probability of non-spread of bone cancer if the affected part is amputated, is due to the use of medical statistics as a microscope which has always been used on observed data to separate the chaff from the wheat and indeed the diseased from the healthy. Not that alone, it has been used to identify the risk factors of diseases. Medical Statistics has made it possible to associate with heart attack, the case of a 55 year old prosperouslooking man who alighted from his new Mercedes Benz Jeep which he drove by himself from his station of about $200 \mathrm{~km}$ away, entered his father's compound safely and suddenly slumped in the process of prostrating before his father and was declared dead a few minutes later! Or else the witches in the family could have been held responsible. The amount of statistical jargon found in any medical journal today is an eloquent testimony to the use of this science to understand health and diseases.

\section{Some other Specific Applications of Statistical Concepts to Medicine \\ Control of Communicable Diseases}

Several hypotheses based on quantitative data have been evaluated through the application if mathematical models. The earlier area of mathematical application to the development of medicine was in the area of communicable diseases. It will only be important to mention a few in this lecture. Following the successful fitting of the normal curve by William Farr in 1840 to quarterly data on deaths from smallpox, further application was for the description of epidemics. Notable is the work of Ronald Ross on the transmission of malaria by female anopheles mosquitoes. Simple mathematical assumptions already postulated by Hammer in 1906 that the net rate of spread of infection is proportional to the product of susceptibility and the density of infections of individuals, and that they are expressed in a discreet time was all he needed to establish the popular threshold theory for malaria, but after the modification of the model to a continuous time frame (Bailey 1957, 1975). The only snag in the application of mathematical models to disease and health is the lack of empirical data and this has sometimes defeated the whole exercise. 
In fact, a look at literature reveals that less than $10 \%$ of published mathematical models in medicine have practical applications due to lack of empirical observations. But more data-oriented studies of diseases using mathematical theories are coming up. For example, the current public health policy on diseases such as onchocerciasis and malaria has benefited from the mathematical theories developed that were necessary and sufficient to recommend effective methods of controlling the sources of infection. In the earlier stage of my career, I was introduced to the control of onchocerciasis (river blindness) and my humble contribution was in the statistical analysis of the drug trial. The analysis examined the relative efficacy of Banocide and Suramin Injections on the disease (Bamgboye 1977). Studies later revealed that mathematical models can be applied to determine the point of intervention for effective control and I was invited to Ouagadougou by WHO to participate but the load of work in Ibadan prevented me from continuing with them. However, today, the model developed by other medical statisticians who finally worked on the research has led to the effective control of the disease.

Decision making in medicine has benefited from mathematical statistical theories appropriately facilitated by Baye's Theorem. It has been discovered that, no investigation can be called true science without passing through mathematical tests. Thus, the reliability and validity of most diagnostic tests commonly used in medicine today have been developed through mathematical concepts of statistics. For example, the probability that a patient has a particular disease if the diagnostic test is positive given the prevalence of the disease in the population and the false positive rate, can only be calculated by statistical methods.

Designs of various studies in medicine have benefited through mathematical knowledge. Initially, Mathematicians or Statisticians were used for technical service in the analysis of data but in recent times, the notion has changed and the collaborative role of statisticians in the development of treatment strategies in medicine is now well recognized. Observational studies are more common in medicine than real experiments. But the medical domain is beginning to realize that the only way to find out what will happen to a complex system as in medicine is to disturb the system. Several statistical methodologies have been developed to bring out the scientific values of the popular observational studies, particularly in identifying risk factors of diseases or in studies of disease etiology.

The present approach to the control of communicable disease has emerged through the applications of mathematical and statistical theories to the description of the process of acquiring the disease. This has led to the suggestion that, immunization, control of unanimated vehicles of infection, control of insects and other living vectors and appropriate therapy could be basic procedures that could subjugate communicable diseases.
A lack of proper understanding of the host - parasite relationship which expresses the genetic make-up of the system has slowed down the control of many infectious diseases. However, a model has been developed that is essential to describe, predict, and explain our health situations. That this is possible has been through mathematical reasoning and logic. A clear understanding of the transmission process of epidemic has thus benefited from mathematical methods. Another basic reasoning is the phenomenon developed by Reed Frost in 1928 and further explained by Greenwood in 1931. They both stipulate that the probability of a given epidemic chain is the product of probability terms from different binomial distributions. This is the population chain binomial model which has found immense use in the description and prediction of the rates of infections and has led to the telescopic value of medical statistics for predicting future occurrences of epidemics based on observed facts now, if nothing is done.

A major contribution was the work of the first Ph.D. candidate produced in Medical Statistics in this University, Dr. Bidemi Oyindamola Yusuf, who under my supervision applied mathematical models to unravel the problem of anti-malaria drug resistance which permeates the population (Yusuf, 2005). This thesis developed a mathematical framework to explain and describe the population dynamics of drug resistance, using stability analysis and simulation. It revealed that it was more beneficial to prevent drug resistance than to cure it.

\section{My Contributions}

Mr. Vice-Chancellor sir, let me at this point talk briefly about the role of the medical statistician and my contributions to my profession. It is a common mistake to assume that medical statistician need only be concerned with the analysis of already collected medical data. This is of course the notion of many other workers about medical statisticians working in a medical milieu as in the College of Medicine. It is no doubt that the medical statistician plays a major role as a data analyst but he/she does equally well in study design and conduct. One of the duties of a medical statistician is collaboration and his/her role in such a situation is to ensure that both protocol design and interpretation of study and trial findings conform to sound principles of scientific investigation that will remind us that the cause of humans' health and disease is such that cannot be easily seen with the naked eye.

Apart from collaborative research, a good medical statistician, as a scientist especially one who works in the academia has his own special area where he should make novel contributions. I will now describe where I have made novel contributions as an individual or in collaboration with others. This will also include my role in the Development of Medical Statistics Education in the University of Ibadan. 


\section{My Contribution as a Collaborative Scientist}

Ever since I joined Professor Ayeni at the University of Ibadan in 1975, I have used medical statistics as the instrument to search for the truth of health and disease, a task tantamount to a blind man looking for a black cat in a dark room. The first aspect of my contribution was through collaborative research and to date, I have collaborated with 177 medical persons or researchers to solve or throw light on a number of medical problems or issues both in Nigeria and Saudi Arabia. It is interesting that I have only $\mathbf{8}$ non-medical people as collaborators. I have also been involved in 27 national health studies both in Nigerian and Saudi Arabia and over 5,000 on-the-spot statistical consultations averaging one per day.

This aspect of my work brought some confusion to some naive scientists saddled with the task of reviewing my publications for professorship as to whether they should recommend me for Professor of 'Obstetrics and Gynecology? Pediatrics? Medicine? Ophthalmology? Psychiatry? Demography? Medical Education? Or Pathology?' (Name any area of Medicine except Surgery which has just begun to have its doses of the use of medical statistics). And this is simply because of my numerous scientific publications with collaborators in these specialties. But most importantly, what is medical about the professional medical statistician that I am? This is that the medical statistician has a fair amount of medical knowledge, medicine being the subject matter of his field. But the medical statistician is no more a doctor manqué than he is a mathematician manqué. Since he is involved in collaborative work, his collaboration shall not be wasted if the medical member of the research team takes time to explain things taught to medical students in their first pre-clinical years to him. The new professional medical statistician will like to learn among other things, in an apprentice fashion on the job, some of the medical knowledge, no one is allowed to advice on a subject he does not understand. This implies that the medical statistician obtains enough materials on any medical topic brought to him for statistical advice and he is expected to have a fair knowledge of this before offering any advice.

My collaborative role in the application of statistical methodology to the design, analysis and interpretation of medical studies underscores the good proportion of my publications in various specialties of Medicine. As is well known, my collaborators are medical people and I am happy to say that my collaborative research work is not limited to the shores of Nigeria but to far away Saudi Arabia where, during my initial short stay of about 3 years at their first College of Medicine, King Saud University, Riyadh (although I had an aggregate romance close to 12 years), I was able to produce 30 publications. At this point Mr. Vice Chancellor, I like to say that the credit of authorship, according to the International Committee of Medical Journals, should be based and it is based on:
(1) substantial contributions to conception and design of a study, or acquisition of data, or analysis and interpretation of data;

(2) drafting the article or revising it critically for important intellectual content; and

(3) final approval of the version to be published.

Authors should meet conditions 1, 2 and 3, I recommend considering these criteria of assessing contributions in multiple author publications, in the University of Ibadan, new guidelines for the promotion of academic staff.

I am bold to say that in all my collaborative work, regardless of my position in the authorship list, I met all 3 criteria. In Pediatrics, working in collaboration with others in Saudi Arabia, a standard growth chart for monitoring the growth of children was developed based on a national cross-sectional study to replace the American Reference Standard which was found not suitable for Saudi Arabia children (al-Frayh and Bamgboye 1992, 1995; al-Nuaim and Bamgboye, 1995, 1996; al-Sekait et al., 1992). The curves were drawn using the Spline Polynomial Regression Method and it is used in all clinics in Saudi Arabia to monitor the growth of children. Another contribution in Paediatrics was the identification of factors influencing linear growth in children (al-Fawaz and Bamgboye 1994), the results of which have helped in health promotion programmes. So also was the study on the determinants of faltering growth in Saudi Children (Bamgboye and al-Nahedh, 2003). Other studies included 'Bronchial Asthma in Saudi Arabia' and the determination of the risk factors of Coronary Artery Disease in Nigerian and Saudi Arabia (Taylor et al., 1996; al-Nozha et al., 1994). Another area was in the determination of visual loss in Saudi Arabia (Badr and Bamgboye 1990, 1992). Studies on the causes of adult morbidity also provided a good benchmark for planning preventive actions (alBalla et al., 1993; Bahakim et al., 1993).

In Nigeria, basic data on morbidity showing the type and pattern of disease in our children received my attention (Bamgboye and Familusi, 1990). So also, was the utilization of health services in the hospital (Bamgboye and Jegede, 1987; Jegede et al 1990, alShammari et al., 1994), (Bamgboye and Shoge, 1987; Bamgboye, 1985). This concept has been of help to policy makers examining the burden of disease. Also hospital administrators benefited from studies on waiting time of patients in the hospital before seeing a doctor (Bamgboye, et al., 1992; Bamgboye and Jarallah 1994). I have also collaborated with colleagues in Psychiatry to study health problems of the elderly (Baiyewu et al., 1997; al-Shammari et al., 1994). Indicators of morbidity in workers, using sickness absence records, have also been analyzed to produce relevant morbidity statistics both in Nigeria and Saudi Arabia (Erinosho and Bamgboye, 1998; Bamgboye and Adeleye, 1992; Bamgboye et al., 1994; al-Shammari et al., 1994). 
Another area of my contribution is in the development of health service research in Nigeria. The availability of reliable morbidity and mortality data serve as evidence of good database for better planning of health service and effective health policy. In this respect, I have been involved in the national health information system and the development of techniques for estimating the burden of disease in Nigeria, (Taylor and Bamgboye 1979; Taylor et al., 1992). Part of my contribution has been to a number of national studies carried out by the Federal Ministry of Health with support from numerous foreign donors. These include National Health Surveys for the determination of levels of reproductive health including HIV/AIDS (Federal Ministry of Health, 2005), the Evaluation of Prevention of Mother to Child Transmission of HIV/AIDS in Nigeria (FMOH, 2005) and Sentinel Surveys for the Estimation of the Prevalence of HIV in Nigeria (FMOH, 2006). The later report has informed the present scaling up of the programmes and refinements in the logistics. A national behavioral surveillance survey of high risk groups of HIV/AIDS in Nigeria has just been concluded and the report is yet to be published. The information from the various surveys benefiting from the science of Medical Statistics has been useful to policy makers in determining the current health and disease status of Nigerians for effective health service planning and development of strategies to aid the campaign against HIV / AIDS.

Let me also add that I have collaborated with colleagues in the Department of Obstetric and Gyneacology to contribute intellectually to reproductive health research. The objectives of our Lord as contained in Genesis 1 verse 28 which says: "Be fruitful and multiply and replenish the earth..." can be realized with good healthy reproductive practices. Studies on the growth patterns of the fetus at different gestational ages in a normal obstetrics population have produced appropriate techniques for measurements of fetal growth and standards for evaluation (Osinusi and Bamgboye, 1987; Marinho and Bamgboye, 1987). The studies on the evaluation of ante-natal services in Saudi Arabia have helped to develop a sound policy on the number of antenatal visits and the provision of maternity services in general (al-Nasser et al., 1991, 1992 and 1994). Other contributions were in the area of the determinants of abortion and reproductive potentials following abortions as well as ectopic pregnancies. The information has been a useful guide for health education and obstetric practices (al-Nuaim et al., 1995; Adelusi et al., 1998).

\section{My Contribution to the Science of Medical Statistics}

My Ph.D. thesis on the Methodology of Indirect Techniques is one of my major contributions to Medical Statistics. The outcome of this Ph.D. degree work is now a central item in the United Nations Manual X for Indirect Demographic Methods (U.N. Manual X, Chapter IV, 1983). The methodology developed under the supervision of Professor Brass, the father of Medical Demography is one of the great topics in courses on Indirect Techniques today. It is known as the Brass-Bamgboye technique for locating time points for adult mortality estimation from retrospective survivorship data (Brass and Bamgboye, 1981; Bamgboye 1983). It was a great delight when Professor Ken Hill, the greatest living icon in Indirect Demographic Techniques at the John Hopkins University in April this year introduced the topic in a lecture on Indirect Methods and declared it as one of the greatest contribution to indirect methods for mortality estimation. He further challenged me to have a closer look at the methodology for possible refinements (if necessary) in the light of new available data. Fortunately, we now have a programme for a Ph.D. in Medical Demography in my department and one of our promising, young and talented lecturers in Medical Statistics, Odunayo Akinyemi has turned his microscope in this area to search for more truth in pursuit of his Ph.D.

\section{The Indirect Method of Estimating Mortality (Medical Demography)}

For the benefit of the audience, let me talk briefly on Indirect Demography Techniques. The numerator for mortality indices can be obtained directly from records of deaths collected routinely through the vital registration system and its denominator from census figures (Bamgboye, 1983). It suffices to mention the lack of traditional demographic data in developing nations where the organization of national census or the establishment of vital registration systems continues to be a problem (Ayeni, 1971). The childhood survivorship data obtained from simple questions for mother on total children ever born and numbers surviving are known to provide good estimates of infants and childhood mortality (Brass and Hill, 1973). So also, reports on orphan hood and the everwidowed have provided acceptable adult-mortality levels (Hill, 1977). These estimates are obtained from simple questions such as 'Is your father alive? Is your mother alive? Is your spouse alive? And so on requiring Yes or No answer and included in single round demographic surveys. The underlying assumption of the methodology has been that mortality changes in the past can be ignored or that mortality remains constant. My novel contribution to this issue is the examination of this assumption and development of a mathematical model that locates the time in the past to which the estimates of mortality levels from these retrospective survivorship reports refer (Brass and Bamgboye, 1981; Bamgboye 1983). My contention is that mortality in developing countries cannot and is not constant but changes. In the light of many economic development and social strategies it should be declining. However, this decline is assumed to be on the logit scale.

These methods have been developed using sound mathematical theories such as the Taylor's series theory used to link cohort life tables with period life tables. The development of the model was based on several assumptions of fertility and mortality regularities and population models utilizing theories of integral calculus, 
power series and the logic models. The evaluation has resulted in the equation for the time location $(\mathrm{T})$ in the past given as:

$$
\mathrm{T}_{1}=\frac{\int_{\mathrm{x}} \int_{\mathrm{ax}} \mathrm{W}_{\mathrm{a}}\left(\ell((\mathrm{a}+\mathrm{x}) \mathrm{T}) / \ell(\mathrm{a}, \mathrm{T})\left({ }_{\mathrm{x}} \mathrm{L}_{\mathrm{a}-\mathrm{x}} \ell(\mathrm{a}, \mathrm{T}) \mathrm{dadx}\right.\right.}{\int_{\mathrm{x}} \int_{\mathrm{a} x} \mathrm{~W}_{\mathrm{a}}(\ell((\mathrm{a}+\mathrm{x}) \mathrm{T}) / \ell(\mathrm{a}, \mathrm{T})-\ell((\mathrm{a}+\mathrm{T}), \mathrm{T}) \mathrm{dadx}}
$$

$\mathrm{W}_{\mathrm{a}}=$ proportion of the group in the age group $(\mathrm{a}, \mathrm{a}+\mathrm{x})$

$\int_{\mathrm{x}} \int_{\mathrm{a}}=$ Integral signs at which persons enter the system (a) and appropriate lengths of exposure respectively

(The system may be marriage or orphanhood)

$\ell((a+x), T)=$ Life table survivorship to $a+x$ at time period $\mathrm{T}$

This model, developed for estimating time location of estimates obtained from retrospective survivorship reports may look complex. And this underscores researchers' view that while a physician is said to make an analysis of a complex illness, a statistician makes one ill with complex analysis and this may explain why a physician is held in higher esteem than the medical statistician. But the interest in the medical field is more of the application and results rather than the complex methodology.

My interest in the development of mathematical models had encouraged me to estimate indicators for health and diseases for countries with poor and deficient data. The work has facilitated my estimating fertility and infant mortality levels for Saudi Arabia and South West Nigeria (Bamgboye 1989, 1990, 1993; Al-Nasser and Bamgboye, 1992).

A disease surveillance and notification system for monitoring the expanded programme on immunization was also developed in the 1908 s while I was working as consultant to the UNICEF office in Nigeria through the establishment of sentinel sites (Bamgboye, 1988).

\section{Development of Medical Statistics Education}

The science of Medical Statistics was at its infancy when I joined the then Department of Preventive and Social Medicine as there was only person in the unit. This was the first Professor of Medical Statistics in Africa and one of the 3 pioneers of the programme of Medical Statistics at the University of London, School of Hygiene and Tropical Medicine - the renowned Professor Olusola Ayeni. A statistically significant information is the fact that I was in the $7^{\text {th }}$ set of students that drank from the fountain of Medical Statistics at the London School of Hygiene and Tropical Medicine. Suffice to say that the growth of Medical Statistics in Ibadan today was master-minded by the doyen of Public Health worldwide - our own Professor Adetokunbo Lucas whose dynamism and brilliance has led to what we witness today. My experience has shown that Medical Statistics is not an attractive subject to the medical student. Perhaps they do not understand the doctrine it is preaching at the time it is introduce to them. Therefore, my knowledge of the psychology of students to mathematics, and particularly of medical students and others in the allied health professions who had thought the only microscope they need is to read slides on patients from the pathology and hematology laboratories diagnoses has led me to find simple innovative ways to teach the Medical Statistics course. A simple textbook was produced based on the earlier approach by Professor Lucas (Bamgboye, 2004). The approach has popularized the Medical Statistics course and this has increased the interest of students and staff in a subject hitherto regarded as relatively difficult.

\section{Design of Medical Experiments}

Another area of my contribution is in the design and analysis of various medical experiments. It is important to note that properly designed and well analyzed clinical trials have resulted in bringing to light appropriate prophylactic and therapeutic treatments of major diseases. Many treatments or procedures today have emerged through experiments aptly designed using the mathematical approach. To come to this stage has not been a smooth journey as the statistician suggests elements of randomization to avoid bias and at times recommends blindness as a measure to avoid both subject and assessments bias. The physician holds a contrary view that he has to know and be in control of the drugs or treatments given to his patients, and does not subscribe to chance in determining the dosages or treatments.

The picture today is that no treatment or drug can be introduced into the market without undergoing clinical trials heavily policed by medical statisticians. In fact, for drugs developed in other countries and which have undergone clinical trials in those countries, the regulation body in Nigeria, NAFDAC requires a repeat of such clinical trials using Nigerian subjects. To this end, our drug companies are often testing new drugs for the treatment of urological problems, chronic diseases such as hypertension and diabetes. My major contribution in this regard has been either in the design or statistical analysis of data collected during these drug trials. For example, one major contribution was in the study design and statistical analysis of multi-centre drug trial in Niprisan, a drug for the control of sickle-cell disease (SCD) in Nigeria. This drug was recently launched in Abuja with the trade name Nacosan (Wambebe et al. 2001; Bamgboye, 2006).

Other clinical trials I have participated in include - just to mention a few:

(1) Anastrazole trial in the treatment of Breast Cancer; (Bamgboye, 2006).

(2) Open label, flexible dose escalation study to assess the efficacy and safety of Doxazosin (Cardura) in patients with benign prostatic hyperplasia; (Bamgboye, 1999). 
(3) The effectiveness and safety of an individualized Symbicort Turbuhaler maintenance dosing regimen (Symbicort Asthma Control Plan) versus Symbicort Turbuhaler given as standard regular twice daily therapy - The Symbicort Adjustable Maintenance Study (SAM), (Bamgboye, 2001).

(4) A multi-center open label assessment of the efficacy and safety of Atorvastatin (Lipitor) in the treatment of Types IIA \& IIB Hyperlipoproteinemia (Bamgboye, 2003); and

(5) Viagra for erectile dysfunction.

This microscope is not only towards health and disease but also to allied areas where the truth is needed. Such is the performance of students in the university and their admission criteria. My work in this area has been in examining the University of Ibadan as a case study. This effort resulted in the present admission guideline for Post-UME screening referred to as the Ibadan Model, (Bamgboye, 1981; Bamgboye et al., 2001; Kale and Bamgboye, 1984; and Ibadan Post-UME Screening Committee, 2005).

\section{The Growth of Medical Statistics in the College of Medicine}

Mr. Vice Chancellor sir, this inaugural lecture would not be complete if I fail to speak on the growth of Medical Statistics in the College of Medicine. The story would have been "sweeter in the mouth" of Professor Ayeni, who created the path for me to follow but he did not have the benefit of an inaugural lecture before he retired from this university in 1985. A look at the records of inaugural lectures in the University revealed a deficient data system as we can only estimate that only 200 professors have given since 1949 . The lecture that I am giving today is the $35^{\text {th }}$ of all inaugural lectures from the Faculty/College of Medicine which has produced $17 \%$ of all inaugural lectures ever-given in the university. As at today, there are 57 professors in the College of Medicine.

\section{Medical Statistics in the Training of Undergraduate Medical Students}

As earlier mentioned, Professor Adetokunbo Lucas, the doyen of Public Health introduced medical statistics into the medical curriculum of the University of Ibadan and taught the course himself until 1969. Because of his understanding of the multi-disciplinary nature of public health, he recruited the first professional medical statistician, Professor Olusola Ayeni in 1968. Thereafter, Professor Lucas established a special unit of medical statistics and realizing its uniqueness to medical research and practice, located the unit in the first floor of the new Clinical Science Building housing the other players of the medical profession (Surgery, Medicine, Pediatrics and Obstetrics and Gyneacology). The experiences as told by the 'Mungo Park' of medical statistics in Africa was that of ignorance of this new discipline that found its root in medicine and medical research. The Medical Statistics course was taught to medical students for only 8 hours as part of a course in the pre-clinical years but was initially never examined.
When the senate finally approved that the course be examined under Biochemistry, Professor Ayeni told me of a story of the Head of Biochemistry setting questions on Biostatistics, a course he taught as a medical statistician. And unfortunately, the question was like a sentence with neither a verb nor a predicate. It took the poorest student to point out this mistake. It came to the open and the senate queried the professor of Biochemistry who replied that the senate when approving the inclusion of Biostatistics as an examinable course in the medical curriculum did not specify who should set the questions. There are no two 'Lucases' when we talk of public health in University of Ibadan. However, all researchers in medicine at that time benefited from the only medical statistician in the first 5 years that they clamoured for another one. Topics and terms like Chi-Square (X2), Regression, Correlation, P-Value, Ramdom Sample, t-test, ANOVA, have developed deep roots in medicine as they form a compulsory part of the undergraduate medical curriculum. But my experience has shown that medical statistics is not an attractive subject to any medical or para-medical student. There was in fact a dialogue with some medical students who wanted to know from the Professor of Medical Statistics why they need to study medical statistics at all. The professor answered; "because statistics save life." And the students asked, "bow?" The professor answered, "statistics keep all the idiots out of the medical or nursing profession."

\section{Postgraduate Training in Medical Statistics}

One major contribution to knowledge as a Professor of Medical Statistics is the development of the science of medical statistics. Mr. Vice-chancellor sir, I am happy to announce that there has been dramatic progress in this area since 1996/1997 academic session when a sub-department of Epidemiology, Medical Statistics and Environmental Health (EMSEH) was carved out of the Department of Preventive and Social Medicine for administrative convenience. Perhaps it may be illuminating to give some background information on how we came about a sub-department.

\section{The Birth of EMSEH}

It all started when I was appointed as the convener of the 4-man committee set up by the then Provost Professor B. Osotimehin who recommended that PSM should divide into 6 departments for the academic growth of Public Health. It was not an easy task but we managed to get 3 sub-departments of which Epidemiology, Medical Statistics and Environmental Health (EMSEH) was one. Unfortunately, I was in Saudi Arabia when the sub-departments were created.

When I finally returned to Nigeria in 1996, to assume coordination of the sub-department of EMSEH, the situation was like a Yoruba saying which means that "who comes last meets the watery part of the soup". A sub-department, scattered, with not enough office space, poor complement of non-teaching staff, two typist, no secretary, no office for the HOD, and above all, no specific academic programme except the MBBS 
held on to by all members of the College, the only $\mathrm{MPH}$ in Environmental Health programme still being contested, and so on, was all that was inherited. It is to the Glory of God that today, we are not a subdepartment but a full department in the Faculty of Public Health with well-defined academic programmes.

\section{Postgraduate Education}

The first step was to initiate the development of postgraduate programmes and because of the staff strength and mix then - four epidemiologists, two medical statisticians and one environmental health specialists, we decided to start with a Master's degree programme in Epidemiology and Medical Statistics and we relied largely on part-time lecturers. Incidentally, before my final return to the Department in 1996, Professor Ayeni and I, had discussed the possibility of a Masters Programme in Biostatistics and he assured me of the support of WHO through its special programme on Human Reproductive Health Research and Development in which he was the Chief Medical Statistician, and with his technical support and that of Professor Oluwole Akande, who was Project Manager of HRP in the WHO at that time, the proposal for an M.Sc. degree in Biostatistics was approved in principle.

The WHO support for this course which includes scholarship for some students, building capacity to strengthen the academic staff and enhance computer facilities, library and communication equipment, was implemented in the 1998/1999 academic session. Since its inception, the programme has trained 103 professional biostatisticians and epidemiologists, both male and female, at the Master's degree level (see Table 2). Of these, eleven were foreign students from other African countries such as Ghana, Kenya and Cameroon. Four others have already completed their Ph.D. degrees, three in Epidemiology and one in Medical Statistics, two of whom were supervised by me.

Table 2: Distribution of Students' Enrolment for M.Sc. Biostatistics Programme since inception

\begin{tabular}{|l|l|l|l|}
\hline Session & Male & Female & Total \\
\hline $1998 / 99$ & 1 & 4 & 5 \\
$1999 / 00$ & 6 & 2 & 8 \\
$2000 / 01$ & 8 & 5 & 13 \\
$2001 / 02$ & 13 & 4 & 17 \\
$2002 / 03$ & 11 & 1 & 12 \\
$2003 / 04$ & 16 & 1 & 17 \\
$2004 / 05$ & 10 & 1 & 11 \\
$2005 / 06$ & 14 & 6 & 20 \\
\hline Total & $\mathbf{7 9}$ & $\mathbf{2 4}$ & $\mathbf{1 0 3}$ \\
\hline
\end{tabular}

WHO Evaluates of M.Sc. Biostatistics Course The course was evaluated in July 2006 by a team of experts from the World Health Organization and wondered how the thin staff on ground could do such a wonderful job. They interviewed some of the students and read a few of their projects. They concluded that the quality and scope of the Master's programme is comparable to any such programme in the World. The evaluation team recommended continued financial WHO support for the course for at lease a further 2-3 years based on the high level of performance.

\section{Other Master's Programme}

At the instance of the request of the WHO through the Federal Ministry of Health another Master's degree programme in Filed Epidemiology was developed and approved in the 2002/03 academic session in the Department. In the 2003/04 academic session, yet another Master's Course Program, the MPH in Medical Demography, the first of its kind in any African University was developed and approved for the Department. This course however also received some technical support from the Melinda and Gates Institute for Reproductive Health based at the John Hopkins University, USA. Thus today, to the Glory of God, we have 6 Master's degree programmes in the Department.

Mr. Vice Chancellor sir, we need more staff to cope with the heavy academic postgraduate run by our Department. The impact of which has helped research output in the College of Medicine, Federal Ministry of Health and other medical and health agencies in Nigeria.

\section{CONCLUSION}

This lecture has revealed the science of medical statistics as the microscope to understand health and disease. The diagnostic criteria for numerous diseases have been developed using sound statistical theories with the dominant contribution of probability and multivariate analytic technique such as discriminant analysis.

Any medical statistician often gets worked up about other people's activities so that he can make (a number of times) some of them his own and assume full responsibility. One particular attribute of a medical statistician is his being at home with mathematics, having the ability to read the more mathematical literature, to follow mathematical argument and use mathematical tools with some confidence. Every mathematical topic should be of potential interest to a medical statistician but what he needs is the relatively elementary bit. However, the methodologically-oriented statistician is able to make the fullest use of his non-medical basic training and by the generality of his approach, may be successful in developing new and modified techniques that may be of value far outside the immediate context that prompted the works. He should however not leave the task of extracting information from real data to the epidemiologist. Both Medical Statistician and Epidemiologists should foster a symbolic relationship to be more productive. This is the basis of the tremendous strength of the Department of Epidemiology and Medical Statistics from our current Department of EMSEH.

Sadly enough, the practice gaining unprecedented ground in collaborative research between our medical 
researchers and colleagues in foreign countries is that Nigerian is being turned to a mere collecting site, whereby the blood specimens as well as data collected in some major studies (particularly on HIV/AIDS), are sent directly to the foreign partners overseas. In most cases the researcher in Nigeria cannot even access the data after it has been entered into the computer. I make bold to say that this is not a collaborative research!

In any collaborative research, every professional is an equal member of the research team, and so the best time to involve every member, particularly the medical statistician is at the planning stage. This is so that he can contribute technological suggestions about the conduct of the research which may greatly increase its impact or reduce its cost; and he/she can contribute a good deal more than this if he/she has an adequate and broad knowledge of the subject matter, which is often recommended.

There is no amount of statistical message that can bring the truth out of a badly planned study. But a study developed according to statistical science can be corrected for appropriateness of statistical methods of analysis of data if discovered later. From my experience, Medicine contains its full quota of dominant personalities and if one of these can persuade a medical statistician to be processing his data and be providing him with the answers he expects, he will certainly turn the statistician into his technician.

This inaugural lecture has shown beyond reasonable doubt that a medical statistician as a professional understands the real needs of his clients or employer, often very much better than the client himself, and has the ability and status to persuade the client to recognize his own interest and to abandon his less useful flights of fancy. He has a professional skill to recommend from a range of known and trusted techniques, those research methods that in the given circumstance will achieve the required effect at minimum cost and inconvenience to the client; and finally, he has the professional integrity to resign his post or commission if his recommendations are not accepted. This is the true collaboration which I have found myself demonstrating as a medical statistician in the medical milieu.

Thus, if the chief medical director of any hospital or the director of a medical research group needs someone to do routine data analysis, they can hire a well trained statistician or buy a computer; just like what Paul told Corinthians in his first letter in Chapter 7 verse 8 that "they do well". But if they want a real medical statistician, they need to pitch their expectations at a realistic level. In this regard, the medical statistician on their staff can regard him/herself as a member of a group of professionals which cuts across narrow specialties of medicine, that he can give seminars, organize workshops and take part in discussions at which his special problem can be seen in their wide statistical context. As one of my professors at the London School of Hygeine and Tropical Medicine said, "the medical statistician is thus a generalist whose special gift is precisely her lack of specialization". This is the level of collaboration that has a promise. Because in this regard, the medical statistician is to be welcomed in the health or medical domain as an equal colleague with the right of entry, not a cap-in-hand visitor.

The bulk of our health problems in this country can benefit more from a population based approach in which the members of the 'club' of Public Health are endowed with the necessary expertise. The faculty of Public Health in the College of Medicine, University of Ibadan can change the poor health situation in Nigeria if all members of the team come together and throw away what I label professional intolerance. The physician in the group should not arrogate the administrative leadership role exclusively to himself and see others as support staff. The faculty of Public Health should live to the expectations of the founding fathers and develop to a School of Public Health.

The Federal Ministry of Health should set aside 3\% of all allocations to medical statistics. This will help to explain and to assess how remaining $97 \%$ is disbursed and spent.

Today's inaugural lecture calls for celebration as PSM has developed to Faculty of Public Health and my Department of EMSEH for which I am head is almost becoming as large as the old PSM. The Department of EMSEH has been a melting point for professional medical statisticians, epidemiologists and environmental health specialists. Our products are now found in Ghana, Cameroon, Kenya and in virtually all medical research institutions and agencies in Nigeria.

\section{Acknowledgements}

I wish to thank the Almighty God who has made it possible for me to be what I am, especially to stand before you today to give an inaugural lecture, which I had thought has eluded me, as those who became Professors 10 years after me have since given theirs.

I will like to thank my parents, Elder \& Mrs. Jacob Dada Bamgboye of blessed memory who thought it fit to send me to school despite the fact that they had no formal education. I also thank my Uncle, Mr. Emmanuel Ayorinde Bamgboye who exposed me to the University of Ibadan since 1958 when I lived with him to complete my primary school at the Abadina School. I appreciate my late maternal uncle, Chief Ayo Omidiji whom I followed to Ibadan in 1958 and who bought me my first suit in 1966 when I left secondary school and late Chief Titus Oke who coached me at home for the A-levels in Pure and Applied Mathematics in 1967, working sometimes late in the night in spite of his busy schedules.

I am most grateful to Professors M.I. Iro and Opeyemi Ola who first introduced Medical Demography to me as a Subset of Medical Statistics in 1973. I thank the University of Ibadan for employing and allowing me to travel overseas when it mattered to have Master's 
and Doctorate Degrees. In this respect, I want to thank Professor E.O Akande specially, who as Dean of the Faculty of Medicine in 1978, recommended the approval of a leave of absence with pay for me and second day approved the recommendation as Acting Vice-Chancellor. I appreciate my supervisor and mentor, the late Professor William Brass and the contributions of Professors Basia Zaba, John Blacker, John Simon, and M.J.R Healy and the entire faculty members in the London School of Hygiene and Tropical Medicine between 1976 and 1983.

I thank Professor Olusola Ayeni immensely, for bringing happiness to the Department when it mattered, by developing a Master's programme in Biostatistics and for facilitating the financial support for the programme and I also appreciate his intellectual review of the manuscript of today's inaugural lecture. I appreciate highly, late Professor Benjamin Osuntokun for his mentoring, Professor M.T Shokunbi for making good his promise in facilitating the creation of the Faculty of Public Health and support of Professor I.F .Adewole, former Provost of the College of Medicine for the growth of EMSEH.

I thank Professor Adefunke Oyemade who encouraged me to travel to Saudi Arabia, Professor Olu Longe, who submitted my CV to the department of Family and Community Medicine, King Saud University and the then Head of Department there, Prof. Shabrawy Alli, one of the leading Public Health Physicians in the world (Africa) who recommended instant appointment for me on seeing my CV.

I thank my Dean, Professor Akinyele who gave me the opportunity of an inaugural lecture and read through the manuscript for constructive contributions, and I thank all the members of staff of my Department. Permit me to mention Professor J.D Adeniyi, a gentle and honest man to the core, who has inspired me on many occasions in my academic pursuit.

I thank my sister, Mrs. Florence Ogundare Awayino for her kindness to me at all times. I also appreciate Mr. Thompson Akinwunmi for accommodating me in his 10B, Repton Court in Hommerton area during my very first visit to London in 1976. My uncle, Mr. Joseph Omidiji, is also appreciated. He has always stayed with me in times of need.

You will agree that you need to be spiritually healthy according to WHO to be healthy and so I have a full compliment of members of my church from C.A.C. Oke-Agbara, Prophet M.O. Olowere and his wife, our District Superintendent, Pastor Adams and the District Evangelist, Pastor Farayola and a host of other Pastors including Pastors Gbuyiro, Omidiji, Oluwasanmi, and Faturoti, as well as Elders and Deaconesses. I thank them all. I also thank the President of C.A.C worldwide, Pastor (Dr.) E.H.L Oluseye and members of the governing council of Joseph Ayo Babalola University (JABU) headed by the Chairman, Professor A.M. Imevbore and other members of staff.
My appreciation goes to the Alaaye of Efon-Alaaye, Oba (Dr.) E.A Aladejare who is visiting this hall for the $2^{\text {nd }}$ time in a month; his Olori and other sons and daughters of Efon Alaaye present. I appreciate and thank my friend of 43 years, 10 months and 2 days for his care and encouragement in turbulent and difficult times of life. He is on a special assignment in Benue State but had to be here today for this special occasion. I am talking of no less a person than Professor James Oladipo Kolawole, a Professor of Political Science and current Deputy Vice-Chancellor, University of Ado-Ekiti. I am grateful to our senior brother, Mr. Rufus Kolawole for the 201 pounds he gave me in 1981 when University of London demanded some money I did not have before I could be allowed to defend my Ph.D. thesis. I appreciate my two siblings, Mr. Ezekiel Adebayo Bamgboye and Dr. Isaac Adeleke Bamgboye.

Finally, I will like to thank my better half, Mrs. Ebun Ayodele Bamgboye who has just completed her Ph.D. in Virology and currently Chief Technologist, IMRAT, College of Medicine, for her ability to cope with the family situation when I am away on several occasions or come home late from the office.

Lastly and not the least, I will like to pay tribute to my children, Miss Eunice Adeola Bamgboye, the career lady and understanding daughter, my ever smiling son, Ebenezer Adebola Bamgboye and the baby of the family, Dr. Eniola Adetola Bamgboye, who typed a significant proportion of the manuscript for this inaugural lecture.

Thank you and God bless you all.

\section{REFERENCES}

al-Balla S.R., Bamgboye E.A., al-Rasheed R., Sekiat M. A. and Balla M. (1993) Pattern of adult admissions into the medical wards of King Khaled University Hospital, Riyadh, Saudi Arabia. Saudi Med. J. 14(3): 225-229.

al-Balla S.R., Bamgboye E.A., Sekiat M.A. and Balla M. (1993) Causes of morbidity in elderly population of Saudi Arabia. J. Trop. Med. Hyg. 96: 157-162.

al-Fawaz, Bamgboye E.A. and Al-Eissa Y.A. (1994) Factors influencing linear growth in Saudi Arabian children aged 6-24 months. J. of Trop. Peadiatric: 40:235-23.

al-Frayh A.S. and Bamgboye E.A. (1995) A comparison of length, weight and OFC of Saudi full-term newborns with the KACTS and $\mathrm{MOH}$ standard growth charts. Paediatrics review and Communications - An Int. J.: 8:193-201.

al-Frayh A.S. and Bamgboye E.A. and Mousa M.A. (1993) The physical growth chart of pre-school Saudi Arabian Children. Ann. Saudi Med.: 13(2): 1519. 
al-Frayh A.S. and Bamgboye E.A (1992) The growth pattern of Saudi Arabian pre-school children to NCHS/CDC reference population J. R. Soc. Health: 113(5): 234-239.

al-Nuaim A.R. and Bamgboye E.A. (1995) A comparison of the anthropometry of Saudi Arabia male children aged 6-11 years with the NCHS/ CDC reference population J. Medical Principles and Practice. 7:96-103.

al-Nuaim A.R., Bamgboye E.A. and Al-Herbish A., (1996) The pattern of growth and obesity in Saudi Arabian male school children. Int. J. of Obesity and Related Metabolic Disorders 20(1): 1000-1005.

Ayeni O. (1971), Guidelines for the establishment of vital registration system in nigeria. Medical Journal (1) pp 214-217.

Badru I. and Bamgboye E.A. (1990). Survey of eye disease and visual loss in the Eastern province of Saudi Arabia. Report submitted to KKESH, Riyadh, Saudi Arabia. 1-93.

Bailey, N.T.J. (1957). The mathematical theory of epidemics, London: Griffin.

Bailey, N.T.J. (1975). The mathematical theory of infectious diseases and its applications. London: Griffin.

Baiyewu O., Bella A.F., Adeyemi J.O., Bamgboye E.A., and Jegede R.O., (1997), Attitude to aging among different groups in Nigeria. Int. J. Aging and Human Dev. 44(4); 2883-2892.

Health problems and socio-demographic findings in elderly Nigerians. Afr. J. Med. Sci. 26, 13-1.

Bamgboye, E.A. (1997). Sentinel Surveillance System for EPI target disease in Nigeria. Report submitted to UNICEF (Lagos, Nigeria). pp. 1-57.

Comparative study of the performance of students admitted to study medicine and science at the preliminary examination of the University of Ibadan, 1973-1981.

The demographic characteristics of discharge and deaths in a University Teaching Hospital in South Western Nigeria. Nig. Med. Journal. 16(1\&2): 139146. 1985.

Sentinel surveillance system for EPI target diseases in Nigeria. Report submitted to submitted UNICEF (Lagos, Nigeria). pp. 1-57.

Levels and trends in infant and under five year old mortality in South Western Nigeria. Report submitted to USA Agency for CCCD (Lagos, Nigeria). 1-56.

Dating estimates of infant and childhood mortality from child survivorship data with applications. Genu LXV (10): 25-37.

Estimates of infants and childhood mortality levels and trends in rural and urban South Western Nigeria. Res. For. Dev. 10(1\&2): 74-84.
A Statistical report on open label, flexible dose escalation study to assess the efficacy and safety of Doxazosin (Cardura) in patients with benign prostatic hyperplasia, submitted to Pfizer.

The effectiveness and safety of an individualized symbicort Turbuhaler maintenance dosing regimen (Symbicort Asthina Control Plan) versus symbicort Turbuhaler given as standard regularly twice taking therapy. THE SYMBICORT ADJUSTABLE MAINTENANCE STUDY submitted to AstraZeneca.

A Statistical report on a multi-center open label assessment of the efficacy and safety of atorvastatin (Lipitor) in the treatment of types IIA and IIB hyper-lipoproteinemia submitted to Pfizer.

A companion of Medical Statistics. Published by FOLBAM Health Research and Data Management Center. Ibadan.

A statistical report on the prevalence of dyslipidemia in hypertensive and diabetic Nigerian patients.

A statistical report of a multi-centre prospective randomized trial of tamoxifen versus anastrozole as first line hormonal treatment in post menopausal patients with advanced breast cancer in Nigeria. Submitted to Astra, Zeneca

Bamgboye, E.A. and Adeleye A.I. (1992). Sickness absenteeism in a Nigerian Teaching Hospital, East Afr. Med. J.: 69(8): 40-4.

Bamgboye, E.A. and Al-Nahedh., (2003). Factors associated with growth faltering in children from rural Saudi Arabia. Afr. Med. Med. Sci.

Bamgboye E.A. and Familusi J.B. (1990). Mortality pattern at the children emergency room. University College Hospital, Ibadan, Nigeria. Afr. J. Med. Sci. 19(2): 127-132.

Bamgboye E.A. and Jarallah J. (1994). Long waiting outpatients: A target for health education. Pattern education and counseling. 23:49-54.

Bamgboye E.A. and Jegede R.O. (1987). A prospective study of the pattern of utilization of mental health services of a Nigerian University College Hospital. Afr. J. Med and Med. Sci. 16(1):2732.

Bamgboye E.A. and Shoge F.A. (1987). An analysis of in-patient statistics in a Nigerian University College Hospital. West Afr. J. Med. (6 \& 4): 225229.

Bamgboye E.A. and Zoaka A. (2005). A Statistical Evaluation of Prevention of Mother Transmission of HIV/AIDS submitted to the Federal Ministry of Health, NASCAP, Abuja.

Bamgboye E.A., Erinoso H.O. and Ogunlesi A. (1992). The waiting time at the children emergency room of the University College Hospital, Ibadan. Nig. Paediatr. 19(1):9-14, 1992. 
Bamgboye E.A., Ogunnowo B.E, Badru O.B. and Adewoye O.E. (2001). Students admissiom grade and their performance at the Ibadan University Preclinical MBBS examinations. Afr. J. Med. Sci. Vol. 30, pg. 207-211.

Bamiduro T.A. (2005). Statistics and search for the truth: a Biometrician's view. An Inaugural lecture given at the University of Ibadan.

Brass W. and Bamgboye E.A. (1981). The time location of reports of survivorship estimates of maternal, paternal and the ever-widowed. Centre for Population Studies, London School of Hygiene and Tropical Medicine, Occasional paper 81-1:1-18.

Erinoso B.O. and Bamgboye E.A. (1988). Sickness absenteeism in a Nigeria Polytechnic. Afr. J. Med. and Med. Sci. 17(1) 57-61.

Federal Ministry of Health (2005). National AIDS and STI Control Programme: National Situation and Response Analysis of the Health Sector Response to HIV / AIDS in Nigeria.

National AIDS and STI Control Programme: National Health Sector Strategic Plan for HIV/AIDS in Nigeria 2005-2009. Abuja, Federal Ministry of Health

Healy M.J.R. (1977). Does medical statistics exist? A lecture given at London School of Hygiene and Tropical Medicine London.

Hill K. (1977). Estimating adult mortality levels from information on widowhood population students 3. $75-84$

Jegede R.O., Ohaeri J.U., Bamgboye E.A. and Okunade A. O. (1990). Psychiatric morbidity in a general outpatient clinic. West Afr. J. Med. 3: 177187, 1990.

Jewell N.P. (1990). Some statistical issues in studies of epidemiology of AIDS. Statistics in Medicine. 9:1387-1416
Kale O.O. and Bamgboye E.A. (1984). Survey of shot essays type MBBS examination questions in preventive and social medicine at the University of Ibadan. 1975-1979. West Afr. J. Med. 3(1):25-30.

Taylor G.O. and Bamgboye E.A. (1979). Serum cholesterol and diseases in Nigeria. American Journal of Clinical Nutrition 32. 2540-2545.

Taylor G.O., Bamgboye E.A., Oyediran A.B.O.O., and Longe O. (1992). Serum creatinine and prediction formula for creatinine. Afr. J. Med. and Med. Sci. 11:75-81.

Taylor G.O., Oyediran A.B.O.O., Bamgboye E.A., Afolabi B.M. and Osuntokun B.O. (1996). Profile of some risk factors for coronary heart disease in a developing country: Nigeria. Afr. J. Med. and Med. Sci. 25:341-346.

United Nations Manual X (1983). Indirect Techniques for Demographic Estimation. 145-147

Wambebe C.O.N., Bamgboye E.A., Badru O.B., Khamofu I. I., Momoh J. A., Ekpeyong M.U.B.S., Njoku O.S., Bamgboye E. A., Nasipuri R..N., Kunle O.O., Okogun J.I., Enwerem M.N., Audam J.G., Gamaliel K.S., Obodozie O.O., Samuel B., Fojule G., Ogunyale O., (2001). Efficacy of Niprisan in the preventive management of sickle cell patients: Current Therapeutic Research: 62. 1:26-43.

Yusuf, O.B. (2005). The epidemiology, population dynamics and mathematical modeling of antimalaria drug resistance in Ibadan. Ph.D. Dissertation, University of Ibadan.

Zeger, S. (1991). Statistical reasoning in epidemiology. American Journal of Epidemiology, 134: 1062-66.

Zelen, M. (1983). Biostatistical science as a discipline: A look into the future (with discussion). Biometrics, 827-37. 